\title{
The risks of acute exposure to black carbon in Southern Europe: results from the MED-PARTICLES project
}

\author{
Bart Ostro, ${ }^{1,2}$ Aurelio Tobias, ${ }^{3}$ Angeliki Karanasiou, ${ }^{3}$ Evangelia Samoli, ${ }^{4}$ \\ Xavier Querol, ${ }^{3}$ Sophia Rodopoulou, ${ }^{4}$ Xavier Basagaña, ${ }^{2,5}$ Kostas Eleftheriadis, ${ }^{6}$ \\ Evangelia Diapouli, ${ }^{6}$ Stergios Vratolis, ${ }^{6}$ Benedicte Jacquemin, ${ }^{2,7}$ Klea Katsouyanni, ${ }^{4,8}$ \\ Jordi Sunyer, ${ }^{2}$ Francesco Forastiere, ${ }^{9}$ Massimo Stafoggia, ${ }^{9}$ and the MED-PARTICLES \\ Study Group
}

For numbered affiliations see end of article.

\section{Correspondence to} Dr Bart Ostro, Air Pollution Epidemiology Section, Office of Environmental Health Hazard Assessment (OEHHA),

California EPA, Oakland, CA 94611, USA;

Bart.ostro@oehha.ca.gov

Received 3 March 2014 Revised 30 September 2014 Accepted 14 October 2014 Published Online First 10 November 2014

\section{ABSTRACT}

Objectives While several studies have reported associations of daily exposures to PM2.5 (particles less than $2.5 \mu \mathrm{m}$ ) with mortality, few studies have examined the impact of its constituents such as black carbon (BC), which is also a significant contributor to global climate change.

Methods We assessed the association between daily concentrations of BC and total, cardiovascular and respiratory mortality in two southern Mediterranean cities. Daily averages of BC were collected for 2 years in Barcelona, Spain and Athens, Greece. We used casecrossover analysis and examined single and cumulative lags up to 3 days.

Results We observed associations between $\mathrm{BC}$ and all mortality measures. For a 3-day moving average, cardiovascular mortality increased by $4.5 \%(95 \% \mathrm{Cl} 0.7$ to 8.5$)$ and $2.0 \%(95 \% \mathrm{Cl} 0$ to 4.0$)$ for an interquartile change in $\mathrm{BC}$ in Athens and Barcelona, respectively. Considerably higher effects for respiratory mortality and for those above age 65 were observed. In addition, $\mathrm{BC}$ exhibited much greater toxicity per microgram than generic PM2.5.

Conclusions Our findings suggest that $B C$, derived in western industrialised nations primarily from diesel engines and biomass burning, poses a significant burden to public health, particularly in European cities with high-traffic density.

\section{INTRODUCTION}

Previous associations of acute exposure to ambient fine particles (ie, particles less than $2.5 \mu$ in aerodynamic diameter or PM2.5) are well documented. ${ }^{1}$ Since PM2.5 is a heterogeneous mix of solid and liquid particles, however, the specific constituents that are responsible for these findings remain uncertain. The US National Academy of Sciences, ${ }^{2}$ the European Commission II Position Paper on $\mathrm{PM}^{3}$ and the $\mathrm{WHO}^{4}$ have highlighted the importance of identifying the specific particle species that are most harmful to the exposed population. Such knowledge could help prioritise interventions to control ambient air pollution. The importance of this has been highlighted by recent

\section{What this paper adds}

While the adverse health effects of acute exposure to ambient fine particles are well documented, the specific constituents that are responsible for these findings remain uncertain.

- Reducing emissions of one specific constituent of fine particles, black carbon, may produce important co-benefits since it likely has direct impacts on public health and impacts on global climate change.

- Analysing unique daily data collected in two southern European cities, we found that acute exposure was associated with premature mortality from all-cause, cardiovascular and respiratory mortality and mortality for those above age 65 .

- We found a pooled estimate for all-cause mortality, using inverse-variance weighting, of $2.5 \%(95 \% \mathrm{Cl} 0.7 \%$ to $4.3 \%)$ per $\mu \mathrm{g} / \mathrm{m}^{3}$, an estimate that is about 10 times that of PM2.5 on a per unit basis.

- Our results confirm that significant benefits will result from control of black carbon emissions which in Europe are primarily due to diesel-powered vehicles. 
from coal and domestic biofuel combustion. About $75 \%$ of the PM from diesel mobile sources is BC. ${ }^{6}$ In contrast, open biomass burning and domestic use of residential fuels are the primary sources of BC emissions in Asia, Africa and some South America regions. $^{7}$

$\mathrm{BC}$ and EC are not yet routinely measured in Europe. As a result, only a few epidemiological studies of their relationship to mortality or hospitalisations have been conducted. ${ }^{8}$ These studies, and older studies of short-term exposure to black smoke, provide limited evidence that carbon particles are associated with total and cardiovascular-specific mortality and hospitalisation. ${ }^{9}$ Moreover, recent studies have suggested that the climate forcing effects of BC are larger than previously estimated. $^{7}{ }^{10}$ Therefore, reductions in BC could generate important cobenefits when direct health effects are included. However, better identification and characterisation of the health effects of current exposure to BC are needed to assess those benefits.

As part of the MED-PARTICLES project, funded by the European Union under the LIFE+framework, 2 years of daily data on BC from two Euro-Mediterranean cities were collected and analysed: Barcelona, Spain in the Western end of the Mediterranean Basin and Athens, Greece in the Eastern Mediterranean. This affords a unique opportunity to conduct a two-city study of the impacts of BC using a consistent, predetermined methodology with added variability in some of the underlying population characteristics. Below, we report our findings of an analysis of the mortality impacts of $\mathrm{BC}$, more specifically an equivalent black carbon concentration (EBC) derived from optical instruments after conversion using concurrent thermo-optical elemental carbon (EC) measurements. We examine both single-day and cumulative exposures and consider several disease-specific and age-specific mortality categories.

\section{METHODS}

\section{Setting}

Among the 12 participating cities in the LIFE +MED-PARTICLES project, only Barcelona and Athens had available daily levels of BC. Barcelona is located at the western end of the Mediterranean and is mainly polluted by road traffic. With a population of 1.5 million inhabitants in $101 \mathrm{~km}^{2}$ (when referring strictly to the city, but 5.0 million when referring to the metropolitan area which covers $3236 \mathrm{~km}^{2}$ ), ${ }^{11}$ it is one of the most densely populated cities in Europe. Athens, the capital and largest city of Greece, is located on the southeast coast of the Mediterranean. It covers about $450 \mathrm{~km}^{2}$ and has a population of 3 million. The urbanised area is mainly located in a basin surrounded by mountains on three sides and open to the sea from the south.

\section{BC measurements}

$\mathrm{BC}$ is a term representing the mass concentration of light absorbing particulate matter in the air. It is derived by optical techniques on filter-based instruments in real time. Terminology for representing the physicochemical properties and effects of $\mathrm{BC}$ depending on the measurement techniques employed has been recently proposed. ${ }^{12}$ The measurement of absorbance or attenuation is usually converted into mass concentration by means of a conversion factor or mass absorption coefficient (MAC). The MAC is experimentally obtained by comparing absorbance units with concurrent EC concentrations measured by a thermo-optical technique in terms of $\mu \mathrm{g} / \mathrm{m}^{3}$. Specifically, the converted $\mathrm{EBC}=$ Absorbance units/MAC where the conversion factor may vary according to the type of instrumentation used. Therefore, the results of different instruments are comparable because for our analysis, absorbance units are converted into EBC concentrations using the appropriate MACs. For this paper, instead of EBC we retain the term $\mathrm{BC}$ for simplicity.

BC measurements in Barcelona were obtained at an urban background-monitoring site located in southwest of the city from 1 January 2009 through 31 December 2010. The site represents both the pollution of the central areas due to sea breeze transport and that from one of the largest traffic arteries of the city, located at around $200 \mathrm{~m}$ from the monitoring site. The Multi-Angle Absorption Photometer (MAAP; ThermoTM, model Carusso 5012) was used to calculate absorbance from particles deposited on the filter using measurements of both transmittance and reflectance at two different angles. The absorbance was converted to BC (or EBC following the terminology described earlier) mass concentration using a MAC of $9.2 \mathrm{~m}^{2} \mathrm{~g}^{-1}$ was calculated specifically for Barcelona. This was the average value obtained experimentally in situ and simultaneously by determining EC in high volume samples of $24 \mathrm{~h}$ by means of the Thermo Optical Transmittance technique ${ }^{13}$ using the Sunset Laboratory OC-EC analyser and the EUSAAR_2 protocol. These experimental conversion factors were used in this study. ${ }^{14}$

Twenty-four hour concentrations of BC (EBC) for Athens were obtained from the Demokritos Urban Background station (DEM) by means of an AE-31 Aethalometer (Magee Sci., 7 -wavelength model) with the readings at $880 \mathrm{~nm}$ wavelength reported here. BC measurements were available from 1 January 2008 to 31 December 2009. Twenty-four-hour mean values were calculated from measurement data recorded every $5 \mathrm{~min}$. EBC concentrations for Athens were also determined by employing measurements of EC with an in situ thermo-optical instrument operating in parallel at the station during a subsequent period. It was found that the internal MAC $\left(16.6 \mathrm{~m}^{2} / \mathrm{g}\right)$ value employed by the manufacturer of the aethalometer for conversion of attenuation units to EBC concentration provided a valid conversion to EC within $10 \%$ on average. Despite the two different types of instruments used in the two cities, as indicated above, the data were converted into $\operatorname{EBC}\left(\mu \mathrm{g} / \mathrm{m}^{3}\right)$ by using MACs obtained from a callibration of EC values obtained by thermo-optical methods.

The Athens urban background site lies in a field site away from direct emission sources in a vegetated area. The site is in the northeast corner of the Greater Athens Metropolitan Area and is influenced by both the urban area and by incoming air from the northeast representative of regional atmospheric aerosol conditions. Owing to the background nature of this site, located in suburban Athens, direct influence by surrounding sources is minimal and the site is representative of large residential areas of metropolitan Athens. In addition, we examined the correlation among nitrogen dioxide monitors in the metropolitan area since this pollutant is usually highly correlated with BC. The average correlation of data from 11 nitrogen dioxide $\left(\mathrm{NO}_{2}\right)$ monitors (one monitor near the harbour was excluded since it is more likely to be influenced by nearby ship emissions) was 0.64 indicating that the traffic-related pollutants appear to vary reasonably together in the metropolitan area.

Daily data on PM2.5 and $\mathrm{NO}_{2}(24 \mathrm{~h}$ average) were provided by monitoring networks in the two cities. PM2.5 data in Barcelona were obtained using a Grimm optical counter and hourly concentrations were averaged to $24 \mathrm{~h}$. The data were corrected according to the gravimetric method. PM2.5 in Athens was obtained by gravimetric analysis of Teflon filter samples collected over a period of $24 \mathrm{~h}$. For both cities, $\mathrm{NO}_{2}$ data were obtained using the chemiluminescence method. 


\section{Health outcomes and other covariates}

For both cities daily counts of all-cause mortality for all ages were collected (excluding deaths from external causes, International Classification of Disease-ICD9: 001799, ICD10 A00R99), as well as daily counts of cardiovascular (ICD9: 390459, ICD10: I00199), respiratory (ICD9:460519, ICD10: J00J99) and all-cause mortality for those greater than age 65 .

Data on daily mean temperature were collected to control for the potential confounding influence of weather. We also controlled for time-dependent factors such as major holidays, summer vacation periods and influenza epidemics. The latter were identified using national influenza surveillance systems, where available or were identified based on daily counts of hospitalisations for influenza (ICD9: 487, ICD10: J09J11). ${ }^{15} 16$

\section{Statistical analysis}

For this analysis, city-specific Poisson regression models were fitted with adjustments for long-term and seasonal time trends, air temperature, holidays and influenza epidemics. Time trend was adjusted for by introducing the three-way interaction term between year, month, and day of the week. The models were also corrected for over dispersion. This method has been demonstrated to be equivalent to a case-crossover design using a time-stratified approach to select control days. ${ }^{17}{ }^{18}$ By design, this method controls for factors that do not vary with pollution on a daily basis such as age, smoking, body mass index. We controlled for the influence of temperature by modelling high and low temperatures separately. For high temperatures, we calculated the average temperature on the current and previous day (lag 0-1) and fit a natural spline with 3 degrees of freedom on the lagged variable only for days on which the lag $0-1$ of temperature was higher than the median annual temperature for the city as a whole. Similarly, we adjusted for low temperatures by fitting a natural spline with 2 degrees of freedom for the average temperature on previous six days (lag 1-6) only for days on which the lag 1-6 temperature was below the median annual value for the city. ${ }^{19}$ This method accounts for differences in the lag structures and impacts of cold and warm temperatures on mortality while reducing the correlation between the two spline terms. Holidays, summer population decreases and influenza epidemics were fitted using indicator variables. Finally, BC daily measurements were added to the city-specific regression models. We evaluated the lag structure of the association between BC concentrations and daily counts of health outcomes for single day lags of 0,1 and 2 days (lag0, lag1, lag2) and for a 3-day cumulative lag structure (ie, an un-weighted moving average of lag0 through lag2 or L02).

Several sensitivity analyses were conducted. First, following Samoli $e$ t $a l^{15}$ we analysed the data using a time-series Poisson model with penalised regression splines with both 4 and 8 effective degrees of freedom to control for seasonality. Second, we examined two-pollutant models with a regression specification with $\mathrm{BC}$ and $\mathrm{PM} 2.5$, and $\mathrm{BC}$ and $\mathrm{NO}_{2}$. As indicated by Mostofsky $e a^{20}{ }^{20}$ the parameter for PM2.5 represents the difference in disease risk associated with all other constituents.

All results are expressed as \% excess risk, with $95 \%$ CI, relative to the relevant IQRs. All analyses were conducted using Stata statistical software, V.12. ${ }^{21}$

\section{RESULTS}

Table 1 presents descriptive characteristics for mortality, air pollution and temperature for both cities. The mean daily total number of deaths was almost twice larger in Athens (80 for all cause, 36 for cardiovascular and 9 for respiratory causes) than in Barcelona (40 for all cause, 12 for cardiovascular and 4 for respiratory causes). BC mean concentrations were much higher in Barcelona than in Athens, 2.1 and $0.74 \mu \mathrm{g} / \mathrm{m}^{3}$, respectively.

Table 2 presents the estimated \% change in mortality associated with an IQR increase from lag0 to lag2 and L02. Associations between $\mathrm{BC}$ and all natural cause mortality were similar for both sites at all single-day lags, but Athens showed higher risk estimates for the 3-day cumulative average. For example, the estimate at lag1 was $1.8 \%(95 \% \mathrm{CI} 0.3 \%$ to $3.3 \%)$ in Athens and 1.8\% (95\% CI $-0.3 \%$ to $4.0 \%)$ in Barcelona. Statistically significant associations $(p<0.05)$ were observed in Athens for lag1, lag2 and L02 and for Barcelona at L02, with marginal significance $(\mathrm{p}<0.10)$ for Barcelona for lag1 and lag2.

For cardiovascular mortality, the strongest single-day associations with mortality were found at lag2 for both cities, but the risk estimate was twice as large in Barcelona $(5.4 \%$; $95 \% \mathrm{CI}$ $1.7 \%$ to $9.3 \%)$ than in Athens (2.6\%; 95\% CI $0.4 \%$ to $4.8 \%)$ for their associated IQRs. Overall estimates were generally highest for respiratory mortality with both cities reaching statistical significance for L0 and L02. For this end point, estimates for Athens were higher than those of Barcelona.

Pooling the results for the two cities using the 3-day moving average indicated associations with excess risks of $2.5 \%(95 \%$ CI $0.7 \%$ to $4.3 \%), 3.6 \%(95 \%$ CI $0.6 \%$ to $6.5 \%)$ and $8.9 \%$

Table 1 Descriptive statistics for mortality, air pollution and temperature in Barcelona and Athens.

\begin{tabular}{|c|c|c|c|c|c|c|c|c|c|c|c|c|}
\hline Mortality (deaths/day) & $\begin{array}{l}\text { Athens } \\
\text { Mean }\end{array}$ & $\begin{array}{l}2008 / 0 \\
\text { andarc }\end{array}$ & $\begin{array}{l}n=504 \\
\text { leviatio }\end{array}$ & & & & \multicolumn{6}{|c|}{ Barcelona $(2009 / 10), n=595$} \\
\hline All-cause, all ages & $80(12)$ & & & & & & $40(8)$ & & & & & \\
\hline All-cause, age $>65$ & $67(11)$ & & & & & & $35(7)$ & & & & & \\
\hline Cardiovascular, all ages & $36(7)$ & & & & & & $12(4)$ & & & & & \\
\hline Cardiovascular, age $>65$ & $31(7)$ & & & & & & $11(4)$ & & & & & \\
\hline Respiratory, all ages & $9(4)$ & & & & & & $4(2)$ & & & & & \\
\hline Respiratory, age $>65$ & $8(3)$ & & & & & & $4(2)$ & & & & & \\
\hline Pollutants/Temperature & Mean & Min & $25 \%$ & $50 \%$ & $75 \%$ & Max & Mean & Min & $25 \%$ & $50 \%$ & $75 \%$ & Max \\
\hline Black Carbon $\left(\mathrm{ng} / \mathrm{m}^{3}\right)$ & 739 & 48 & 430 & 639 & 932 & 3263 & 2011 & 63 & 1164 & 1818 & 2572 & 8683 \\
\hline PM2.5 $\left(\mu \mathrm{g} / \mathrm{m}^{3}\right)$ & 22 & 5.0 & 16.0 & 20.5 & 26.0 & 62.5 & 17.7 & 1.9 & 11.4 & 15.9 & 21.5 & 59.0 \\
\hline $\mathrm{NO}_{2}\left(\mu \mathrm{g} / \mathrm{m}^{3}\right)$ & 44.5 & 16.7 & 18.5 & 43.5 & 53.7 & 97.5 & 41.5 & 12.1 & 29.5 & 40.3 & 51.3 & 94.5 \\
\hline Temperature $\left({ }^{\circ} \mathrm{C}\right)$ & 19 & -1.7 & 4.6 & 17.9 & 25.7 & 32.6 & 14.1 & 1.0 & 9.1 & 13.8 & 19.5 & 28.3 \\
\hline
\end{tabular}


Table 2 Estimated Effect of Black Carbon on Mortality (\% change and 95\% Cl per IQR change)

\begin{tabular}{|c|c|c|c|c|c|c|c|c|c|}
\hline & \multirow[b]{3}{*}{ Lag } & \multicolumn{4}{|c|}{ Athens (IQR=0.5 $\mu \mathrm{g} / \mathrm{m} 3)$} & \multicolumn{4}{|c|}{ Barcelona (IQR=1.4 $\mu \mathrm{g} / \mathrm{m} 3)$} \\
\hline & & \multicolumn{4}{|c|}{$\%$ change $(95 \% \mathrm{Cl})$} & \multicolumn{4}{|c|}{$\%$ change $(95 \% \mathrm{Cl})$} \\
\hline & & central & low & high & & central & low & high & \\
\hline \multirow[t]{4}{*}{ All-cause } & LO & 1.2 & -0.3 & 2.7 & & 1.4 & -0.7 & 3.6 & \\
\hline & L1 & 1.8 & 0.3 & 3.3 & ** & 1.8 & -0.3 & 4.0 & * \\
\hline & L2 & 2.0 & 0.5 & 3.5 & ** & 1.7 & -0.4 & 3.8 & * \\
\hline & L02 & 2.3 & 0.3 & 4.2 & ** & 2.0 & 0.0 & 4.0 & ** \\
\hline \multirow[t]{4}{*}{ Cardiovascular } & LO & -0.3 & -2.4 & 1.9 & & 0.7 & -2.9 & 4.4 & \\
\hline & L1 & 1.2 & -1.0 & 3.4 & & 2.9 & -0.8 & 6.7 & \\
\hline & L2 & 2.6 & 0.4 & 4.8 & ** & 5.4 & 1.7 & 9.3 & ** \\
\hline & L02 & 1.3 & -1.4 & 4.1 & & 3.9 & 0.6 & 6.5 & ** \\
\hline \multirow[t]{4}{*}{ Respiratory } & LO & 4.4 & 0.2 & 8.8 & ** & 9.1 & 2.8 & 15.8 & ** \\
\hline & L1 & 8.4 & 4.3 & 12.7 & ** & 3.5 & -2.6 & 10.1 & \\
\hline & L2 & 4.8 & 0.9 & 9.0 & ** & 0.5 & -5.6 & 7.0 & \\
\hline & L02 & 8.9 & 3.7 & 14.4 & ** & 6.2 & 0.2 & 12.5 & $* *$ \\
\hline All-cause & LO & 2.3 & -0.9 & 5.7 & & 0.9 & -0.6 & 2.5 & \\
\hline \multirow[t]{3}{*}{ Age $>65$} & L1 & 3.6 & 0.4 & 7.0 & ** & 1.3 & -0.2 & 2.9 & * \\
\hline & L2 & 4.6 & 1.3 & 7.9 & ** & 1.0 & -0.6 & 2.6 & \\
\hline & L02 & 5.0 & 0.8 & 9.3 & ** & 1.7 & -0.4 & 3.8 & * \\
\hline Cardiovascular & LO & -1.0 & -5.3 & 3.5 & & 1.2 & -1.4 & 3.9 & \\
\hline \multirow[t]{3}{*}{ Age $>65$} & $\mathrm{~L} 1$ & 2.3 & -2.1 & 7.0 & & 2.7 & 0.1 & 5.4 & ** \\
\hline & L2 & 5.9 & 1.3 & 10.7 & ** & 3.8 & 1.1 & 6.6 & ** \\
\hline & L02 & 2.7 & -3.1 & 8.7 & & 4.4 & 0.8 & 8.1 & ** \\
\hline Respiratory & LO & 7.5 & -1.3 & 17.1 & * & 6.0 & 1.4 & 10.8 & ** \\
\hline \multirow[t]{3}{*}{ Age $>65$} & L1 & 18.4 & 9.1 & 28.4 & ** & 3.6 & -1.0 & 8.4 & \\
\hline & L2 & 10.4 & 1.8 & 19.6 & ** & 0.1 & -4.4 & 4.9 & \\
\hline & L02 & 17.9 & 6.3 & 30.7 & ** & 6.3 & -0.0 & 13.0 & * \\
\hline
\end{tabular}

${ }^{*} P<0.10 ;{ }^{* *} P<0.05 ; \mathrm{L} 0, \mathrm{~L} 1, \mathrm{~L} 2=$ lags of zero, one and two days; $\mathrm{L} 02=3$ day moving average

(95\% CI $3.4 \%$ to $14.4 \%$ ) per $1 \mu \mathrm{g} / \mathrm{m}^{3}$ for all-cause, cardiovascular and respiratory mortality, respectively. Table 2 also summarises the mortality results for those above age 65 . For both Barcelona and Athens, stronger associations for this subgroup are apparent for all mortality outcomes with risk estimates in Athens approximately double the estimates for those of all ages.

Figure 1 summarises the results of the sensitivity analysis for allcause mortality using the 3-day moving average exposure to $\mathrm{BC}$ for a change in the IQR. The results show that for Athens, the BC only model using case-crossover, the model with both $\mathrm{BC}$ and $\mathrm{NO} 2$ and the time-series model with 4 degrees of freedom all generated central estimates around 2.3\%. Including PM2.5 in the model or using 8 degrees of freedom in the time-series model significantly attenuated the risks estimated for BC. In Athens, the correlation of BC with PM2.5 and $\mathrm{NO}_{2}$ are 0.62 and 0.59 , respectively. Effect estimates for Barcelona were more consistent and had tighter CI with several central estimates close to $2 \%$. Interestingly, adding PM2.5 to the model specification increased the risk estimate for $\mathrm{BC}$ while adding $\mathrm{NO}_{2}$ decreased it. The correlations of $\mathrm{BC}$ with PM2.5 and $\mathrm{NO}_{2}$ were 0.52 and 0.71 , respectively.

\section{DISCUSSION}

We observed associations between daily concentrations of BC and mortality in two Mediterranean cities, Barcelona and Athens. For example, for all-cause mortality, a 3-day moving average in $\mathrm{BC}$ was associated with a $4.5 \%$ (95\% CI $0.7 \%$ to
8.5\%) and 2.0\% (95\% CI 0\% to 4.0\%) for the IQR in Athens and Barcelona, respectively. Much higher risk estimates were detected for respiratory mortality and for mortality among those greater than age 65. These elevated risks are consistent with, among others, those reported in a study of PM2.5 in 27 cities in the USA and with a meta-analysis of world-wide studies of the acute effects of PM2.5.22 23 For those studies conducted in Europe, respiratory mortality effects were about three times those of all-cause mortality and 1.6 times higher than cardiovascular mortality. ${ }^{23}$ We also found that the results were fairly consistent using either case-crossover or traditional time-series methods, although there was greater sensitivity in Athens possibly due to the larger number of missing data. The estimate in Athens was also attenuated when PM2.5 was added to the model specification.

Major differences were observed between BC concentrations in Athens and Barcelona $\left(0.7\right.$ and $\left.1.5 \mu \mathrm{g} / \mathrm{m}^{3}\right)$. This may be a result of three main factors: first, the Athens monitoring site is just outside the central city, whereas the Barcelona site is an urban background site more influenced by the local road traffic; second, the population density of Barcelona is much greater than that of Athens; ${ }^{24}$ and third, the proportion of diesel passenger cars is higher in Barcelona, reaching around 55\% of the fleet and $70 \%$ of annual sales, whereas diesel passenger cars were prohibited from circulating in the city of Athens based on legislation passed in 1991 (since rescinded in 2011). However, 


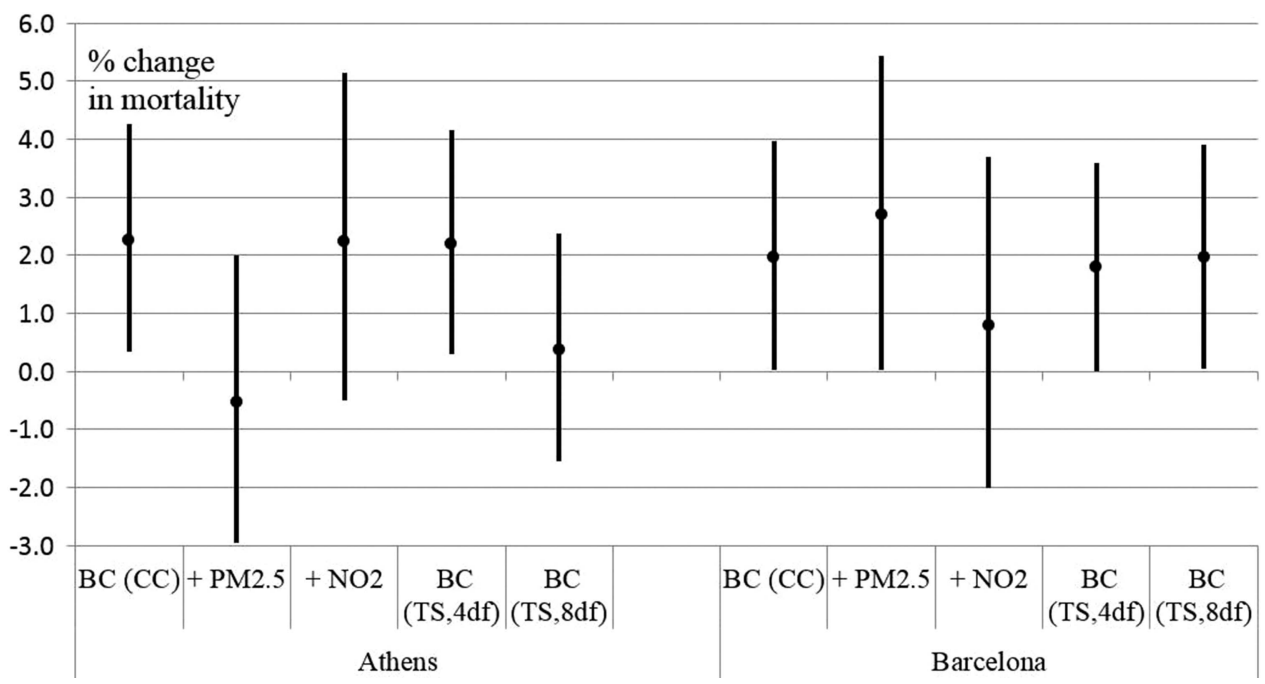

Figure 1 Sensitivity analysis for per cent increase in all-cause mortality associated with an IQR increase using 3-day cumulative average of black carbon (BC). For each of the cities, the order of results is: $\mathrm{BC}$ alone (using case-crossover); $\mathrm{BC}+\mathrm{PM} 2.5$ and $\mathrm{BC}+\mathrm{NO}_{2}$ (using case-crossover), $\mathrm{BC}$ alone (time series, using $4 \mathrm{df}$ ); BC alone (time series, using $8 \mathrm{df}$ ).

taxis and buses were able to use diesel fuel during this period and generate a significant amount of emissions. Based on its location, the monitored concentrations in Barcelona may be high relative to the rest of the city. This may bias downward the estimated effect for a given level of excess mortality and bias upward the IQR. Ultimately, these effects might offset each other. Since the Athens monitor has a suburban location, it is likely a good measure of background exposure but may be low for those living in hot spots in the central city.

While there are few studies of short-term exposure to directly measured BC and mortality, ${ }^{8}$ several studies report associations between $\mathrm{BC}$ and various markers of cardiovascular disease. As such, they add plausibility to the mortality findings by providing some indications of potential mechanisms. For example, in a study of 91 participants with type-2 diabetes, O'Neill et al ${ }^{25}$ reported associations between short-term exposures to $\mathrm{BC}$ and markers of inflammation. Associations for a subset of the markers were observed for BC but not for PM2.5 or sulfate. Likewise, Mordukhovich et $a l^{26}$ found associations for $\mathrm{BC}$, but not for PM2.5, on both diastolic blood pressure and systolic blood pressure in a cohort of elderly men. Short-term exposure to BC has also been associated with ST-segment depression, a sign of ischaemia, in controlled and observational studies. ${ }^{27} 28$ In a controlled exposure study to diesel exhaust, Lucking et al ${ }^{29}$ observed increases in thrombus formation. In addition, recent toxicological studies have demonstrated that animals exposed to diesel exhaust experienced the promotion of growth of atherosclerotic plaque. ${ }^{30} 31$

Associations with short-term exposure to black smoke (BS), a correlate of BC, have also been previously reported. Based on time-series analysis of data from 1990 to 1996 for seven Spanish cities, Ballester $e t a l^{32}$ observed an association between daily BS, measured by reflectometry and total mortality with an estimate of $0.8 \%$ (95\% CI $0.4 \%$ to $1.1 \%$ ) per $10 \mu \mathrm{g} / \mathrm{m}^{3} \mathrm{BS}$. This is equivalent to about $0.7 \%$ per $\mu \mathrm{g} / \mathrm{m}^{3} \mathrm{BC}$ if we apply the BS/EBC ratio developed experimentally from data in the Netherlands. ${ }^{33}$ Katsouaynni et $a l^{34}$ reported a $0.6 \%$ increase per $10 \mu \mathrm{g} / \mathrm{m}^{3}$ increase in BS in total mortality in 14 European cities, including Barcelona and Athens. In addition, a meta-analysis of time-series studies of 26
European cities using data covering 1983 to 1996 reported an estimate of $0.6 \%$ (95\% CI $0.4 \%$ to $0.8 \%$ ) per $\mu \mathrm{g} / \mathrm{m}^{3} \mathrm{BS}^{35}$ Mortality studies of EC have also been conducted. The meta-analysis by Janssen $^{9}$ demonstrated an association with an estimate of $1.45 \%$ (95\% CI $1.3 \%$ to $1.6 \%$ ) per $\mu \mathrm{g} / \mathrm{m}^{3}$ of EC. In an analysis of 72 US urban communities, Krall et $a l^{36}$ reported an estimate of $0.6 \%$ (95\% CI $0 \%$ to $1.2 \%)$. These studies generally relied on single-day lags rather than multiday averages.

Associations with longer-term exposure to $\mathrm{BC}$ have also been reported. Using data from 380 participants of the Normative Aging Study, Wilker et $a l^{37}$ observed an association between 1-year exposure to $\mathrm{BC}$ and increases in carotid intima-media thickness - an early indicator of atherosclerotic disease.

I' $t$ is of interest to compare the relative toxicity of BC to that of generic PM2.5. Using the case-crossover method with a 3-day moving average of PM2.5 for the same years as that of the BC data, we found a pooled estimate for all-cause mortality, using inverse-variance weighting, of $2.5 \%$ (95\% CI $1.1 \%$ to $3.8 \%$ ) per $10 \mu \mathrm{g} / \mathrm{m}^{3}$. In comparison, our pooled estimate for $1 \mu \mathrm{g} / \mathrm{m}^{3}$ of equivalent $\mathrm{BC}$ is $2.5 \%$ (95\% CI $0.7 \%$ to $4.3 \%$ ) so the impact of $\mathrm{BC}$ is about 10 times greater per $\mu \mathrm{g} / \mathrm{m}^{3}$. In a review of studies that included estimates for both EC (based on BS) and PM2.5, Janssen et $a l^{9}$ found that on a per mass unit basis, the risk estimates for EC were 7-8 times that of PM2.5. Likewise, Smith et $a l^{38}$ examined the association of long-term exposure to PM2.5 with EC using the American Cancer Society cohort and reported that the impacts of EC were approximately 10 times that of PM2.5 on a per unit mass basis. Thus it appears that the evaluation of specific properties or sources of PM2.5 is beneficial but not limited to only diesel emissions since other constituents have been identified as toxic.

When comparing the relative impacts of BC and PM2.5 several caveats regarding exposure are necessary. Since PM2.5 is much more spatially homogeneous than $\mathrm{BC}$, exposure misclassification for the latter might be greater, leading to a lower risk estimate, in general. On the other hand, because $\mathrm{BC}$ tends to be in the submicron size range, it penetrates more readily into the indoor environment. For example, in a study of four European cities with paired indoor and outdoor samples, correlations between indoor versus outdoor concentrations were higher for BS than PM2.5 and 
outdoor concentrations explained a greater amount of the variation in indoor concentration. ${ }^{39}$ In addition, during our study period, exposures to BC and PM2.5 were related with correlation coefficients in Athens and Barcelona of 0.62 and 0.52, respectively. Thus, BC is likely correlated with other constituents of PM2.5 and may be a surrogate for their associations. Also, as noted above, there were more missing data Athens and each city had only 2 years of data. It is difficult to weigh the relative impacts of all of these issues in evaluating the per $\mu \mathrm{g} / \mathrm{m}^{3}$ impacts of BC versus PM2.5, but taken together, the toxicity of BC does appear to be much greater than that of PM2.5.

Our results provide evidence for an association of acute exposure to BC on daily mortality, including mortality relating to both cardiovascular and respiratory diseases, and in fact indicate greater toxicity as compared with generic PM2.5. In addition to its importance as a contributor to global climate change, $\mathrm{BC}$ appears to play a vital role in human health. Thus, controlling its sources, such as diesel-fueled vehicles and biomass burning, will help improve urban air quality and, consequently, the health of the exposed population.

\author{
Author affiliations \\ ${ }^{1}$ Air Pollution Epidemiology Section, Office of Environmental Health Hazard \\ Assessment, CAL EPA, Oakland, California, USA \\ ${ }^{2}$ Centre for Research in Environmental Epidemiology, Barcelona Biomedical Research \\ Park, Barcelona, Spain \\ ${ }^{3}$ Institute of Environmental Assessment and Water Research (IDAEA), Spanish \\ Council for Scientific Research (CSIC), Barcelona, Spain \\ ${ }^{4}$ Department of Hygiene, Epidemiology and Medical Statistics, Medical School, \\ University of Athens, Athens, Greece \\ ${ }^{5}$ Universitat Pompeu Fabra (UPF), Barcelona, Spain \\ ${ }^{6}$ ERL, Institute of Nuclear and Radiological Science \& Technology, Energy \& Safety \\ N.C.S.R. Demokritos, Athens, Greece \\ ${ }^{7}$ Centre for Research in Epidemiology and Population Health, INSERM \& UMRS, \\ Villejuif, France \\ ${ }^{8}$ Department of Primary Care and Public Health Sciences, King's College, London, \\ UK \\ ${ }^{9}$ Department of Epidemiology Lazio Region, Rome, Italy
}

Acknowledgements Editorial assistance was provided by Dharshani Pearson and Brian Malig.

Collaborators MED-PARTICLES Study Group: Italy: E Alessandrini, P Angelini, G Berti, L Bisanti, E Cadum, M Catrambone, M Chiusolo, M Davoli, F de' Donato, M Demaria, M Gandini, M Grosa, A Faustini, S Ferrari, FF, P Pandolfi, R Pelosini, C Perrino, A Pietrodangelo, L Pizzi, V Poluzzi, G Priod, G Randi, A Ranzi, M Rowinski, C Scarinzi, MS, E Stivanello, S ZauliSajani; Greece: K Dimakopoulou, KE, KK, AG Kelessis, T Maggos, N Mihalopoulos, S Pateraki, M Petrakakis, SR, ES, V Sypsa; Spain: D Agis, J Alguacil, B Artiñano, J BarreraGómez, XB, J de la Rosa, J Diaz, R Fernandez, BJ, AK, C Linares, BO, N Perez, J Pey, XQ, AM Sanchez, JS, AT; France: M Bidondo, C Declercq, A Le Tertre, P Lozano, S Medina, L Pascal, M Pascal.

Contributors $B O$ and $A T$ conceived the design of the study. ES, MS, FF, KK, SR, $X B, B J$ and JS contributed subject matter expertise, aided in model design and data analysis. $X Q, A K, K E, E D$ and $S V$ contributed exposure data and subject matter expertise. BO, AT, ES, KK, XQ, AK and KE participated in literature review and the drafting and editing of the final manuscript.

Funding This work was supported by European Union grant agreement EU LIFE10 ENV/IT/327. AT was supported by the project PI12/01468, integrated in the National Plan for I+D+I and cofunded by the ISCIII-Directorate General for Evaluation and the European Regional Development Fund (FEDER).

Competing interests None.

Provenance and peer review Not commissioned; externally peer reviewed.

\section{REFERENCES}

1 US EPA. Integrated science assessment for particulate matter (Final Report). In: Agency USEP, ed. Washington, DC, 2009.

2 Committee on Research Priorities for Airborne Particulate Matter NRC. Research priorities for airborne particulate matter: IV. Continuing research progress: The National Academies Press, 2004.

3 CAFE. Second Position Paper on Particulate Matter: European Commission's Clean Air for Europe Working Group on Particulate Matter, 2004.
4 WHO. Review of evidence on health aspects of air pollution-REVIHAAP Project: The WHO European Centre for Environment and Health. Bonn: WHO Regional Office for Europe, 2013.

5 Lim SS, Vos T, Flaxman AD, et al. A comparative risk assessment of burden of disease and injury attributable to 67 risk factors and risk factor clusters in 21 regions, 1990-2010: a systematic analysis for the Global Burden of Disease Study 2010. Lancet 2012;380:2224-60.

6 Ramanathan V. Black carbon and the regional climate of California: California Air Resources Board, California Environmental Protection Agency, 2013.

7 Bond TC, Doherty SJ, Fahey DW, et al. Bounding the role of black carbon in the climate system: a scientific assessment. J Geophysical Res atmospheres 2013;118: 5380-552.

8 WHO. Health effects of black carbon. In: Janssen N, Gerlofs-Nijland M, Lanki T, Salonen R, Cassee F, Hoek G, Fischer P, Brunekreef B, Krzyzanowski M, eds. World Health Organization, Regional Office for Europe, 2012:23-33.

9 Janssen NA, Hoek G, Simic-Lawson M, et al. Black Carbon as an additional indicator of the adverse health effects of airborne particles compared with PM10 and PM2.5. Environ Health Perspect 2011;119:1691-9.

10 IPCC. Climate change 2013: working group I. Contribution to the IPCC Fifth assessment report: The Physical Science Basis. In: Stocker TQD, Plattner G. (ed.) Cambridge, UK: Intergovernmental Panel on Climate Change WMO-UNEP, 2013.

11 Generalitat de Catalunya. http://www.gencat.cat

12 Petzold A, Ogren JA, Fiebig M, et al. Recommendations for reporting "black carbon" measurements. Atmos Chem Phys 2013;13:8365-79.

13 Birch ME, Cary RA. Elemental carbon-based method for monitoring occupational exposures to particulate diesel exhaust. Aerosol Sci Technol 1996;25:221-41.

14 Reche C, Querol X, Alastuey A, et al. New considerations for PM, Black Carbon and particle number concentration for air quality monitoring across different European cities. Atmos Chem Phys 2011;11:6207-27.

15 Samoli E, Stafoggia M, Rodopoulou S, et al. Associations between fine and coarse particles and mortality in Mediterranean cities: results from the MED-PARTICLES Project. Environ Health Perspect 2013;121:932-8.

16 Stafoggia M, Samoli E, Alessandrini E, et al. Short-term associations between fine and coarse particulate matter and hospitalizations in Southern Europe: results from the MED-PARTICLES Project. Environ Health Perspect 2013;121:1026-33.

17 Lu Y, Symons JM, Geyh AS, et al. An approach to checking case-crossover analyses based on equivalence with time-series methods. Epidemiology 2008;19:169-75.

18 Lu Y, Zeger SL. On the equivalence of case-crossover and time series methods in environmental epidemiology. Biostatistics 2007;8:337-44.

19 Chiusolo M, Cadum E, Stafoggia M, et al. Short term effects of nitrogen dioxide on mortality and susceptibility factors in ten Italian cities: the EpiAir Study. Environ Health Perspect 2011;119:1233-8.

20 Mostofsky E, Schwartz J, Coull BA, et al. Modeling the association between particle constituents of air pollution and health outcomes. Am J Epidemiol 2012;176:317-26.

21 StataCorp. Stata statistical software: release 12. College Station, TX: StataCorp LP, 2011.

22 Franklin M, Zeka A, Schwartz J. Association between PM2.5 and all-cause and specific-cause mortality in 27 US communities. J Expo Sci Environ Epidemiol 2007;17:279-87.

23 Atkinson RW, Kang S, Anderson HR, et al. Epidemiological time series studies of PM2.5 and daily mortality and hospital admissions: a systematic review and meta-analysis. Thorax 2014;69:660-5.

24 Ostro B, Tobias A, Querol X, et al. The effects of particulate matter sources on daily mortality: a case-crossover study of Barcelona, Spain. Environ Health Perspect 2011;119:1781-7.

25 O'Neill MS, Veves A, Sarnat JA, et al. Air pollution and inflammation in type 2 diabetes: a mechanism for susceptibility. Occup Environ Med 2007;64:373-9.

26 Mordukhovich I, Wilker E, Suh H, et al. Black carbon exposure, oxidative stress genes, and blood pressure in a repeated-measures study. Environ Health Perspect 2009;117:1767-72.

27 Gold DR, Litonjua AA, Zanobetti A, et al. Air pollution and ST-segment depression in elderly subjects. Environ Health Perspect 2005;113:883-7.

28 Chuang KJ, Coull BA, Zanobetti A, et al. Particulate air pollution as a risk factor for ST-segment depression in patients with coronary artery disease. Circulation 2008;118:1314-20.

29 Lucking AJ, Lundback M, Barath SL, et al. Particle traps prevent adverse vascular and prothrombotic effects of diesel engine exhaust inhalation in men. Circulation 2011;123:1721-8.

30 Cassee FR, Campbell A, Boere AJ, et al. The biological effects of subacute inhalation of diesel exhaust following addition of cerium oxide nanoparticles in atherosclerosis-prone mice. Environ Res 2012;115:1-10.

31 Bai N, Kido T, Suzuki H, et al. Changes in atherosclerotic plaques induced by inhalation of diesel exhaust. Atherosclerosis 2011;216:299-306.

32 Ballester F, Saez M, Perez-Hoyos S, et al. The EMECAM project: a multicentre study on air pollution and mortality in Spain: combined results for particulates and for sulfur dioxide. Occup Environ Med 2002;59:300-8.

33 Schaap M, Denier van der Gon H. On the variability of black smoke and carbonaceous aerosols in the Netherlands. Atmospheric Environ 2007;41:5908-20. 
34 Katsouyanni K, Touloumi G, Samoli E, et al. Confounding and effect modification in the short-term effects of ambient particles on total mortality: results from 29 European cities within the APHEA2 project. Epidemiology 2001;12:521-31.

35 Anderson HR, Atkinson RW, Peacock JL, et al. Meta-analysis of time-series studies and panel studies of particulate matter (PM) and ozone (O3): report of a WHO task group. In: WHO (ed.), Europe: WHO Regional Office for Euope, 2004:4.

36 Krall JR, Anderson GB, Dominici F, et al. Short-term exposure to particulate matter constituents and mortality in a National Study of US Urban Communities. Environ Health Perspect 2013;121:1148-53.
37 Wilker EH, Mittleman MA, Coull BA, et al. Long-term exposure to black carbon and carotid intima-media thickness: the Normative Aging Study. Environ Health Perspect 2013;121:1061-7.

38 Smith KR, Jerrett M, Anderson HR, et al. Public health benefits of strategies to reduce greenhouse-gas emissions: health implications of short-lived greenhouse pollutants. Lancet 2009;374:2091-103.

39 Gotschi T, Oglesby L, Mathys P, et al. Comparison of black smoke and PM2.5 levels in indoor and outdoor environments of four European cities. Environ Sci Technol 2002;36:1191-7 